\title{
FILTRATION OF DISSOLVED ORGANIC NUTRIENTS FROM FISH FARM WASTEWATER USING A MACROALGAE BIOFILTER
}

\author{
JACK R. HALL ${ }^{*} \&$ GEORG MARTIN \\ Estonian Marine Institute, University of Tartu, Estonia
}

\begin{abstract}
Intensive animal aquaculture damages the environment by releasing large quantities of nutrients which drives eutrophication in aquatic ecosystems. Macroalgae are efficient in uptaking nutrients as they grow with past studies suggesting their integration into aquaculture systems as a means to improve wastewater quality. This study was designed to assess the feasibility of using macroalgae as a biological filtration system for the removal of dissolved nutrients found in finfish farm wastewater. To test this, an experimental fish farm and mesocosm system was established on the northern coast of Saaremaa island, West Estonian archipelago. The green algae Ulva intestinalis was selected as a good candidate to assess the efficacy of a macroalgae biofiltration system to uptake nutrients. The results obtained show at best a $18-25 \%$ reduction in waste water nutrient concentrations for the nitrogenous compounds nitrite and nitrate for mesocosms stocked with macroalgae compared with the control. The system experienced an average $60 \%$ reduction in nitrogen and phosphorus concentrations in wastewater outflow compared to concentrations present within the finfish mesocosm. Additionally, the subsequent biomass gain of the incubated macroalgae species Ulva intestinalis is reported to be $4 \%$ per day at its maximum rate. The results obtained in this study indicate that Ulva intestinalis can be integrated into aquaculture systems as a nitrogen biofilter. In addition, the macroalgae biomass produced may offer aquaculture operations an additional income stream improving farm economics.
\end{abstract}

Keywords: aquaculture, biofilter, macroalgae, nutrients, bioremediation, ulva, nitrogen, IMTA.

\section{INTRODUCTION}

The decline of wild fish stocks has necessitated the need for aquaculture to offset the increasing global demand for fish protein [1]. However, as demand for fish protein grows the increasing intensification of finfish aquaculture requires ever greater inputs, in particular, that of fish feed [2], [3]. However, as no operation is $100 \%$ efficient, wastes in such systems are formed as either by-products or as unused inputs. As a consequence, Intensive finfish aquaculture is known to cause several adverse environmental impacts through the excessive output of nutrients, particularly nitrogen and phosphorous, into aquatic ecosystems [4]-[6]. For instance, the production of finfish in Japan has been found to generate on average approximately $0.8 \mathrm{~kg}$ of $\mathrm{N}$ and $0.1 \mathrm{~kg}$ of phosphorus irrespective of fish species cultivated [7]. Furthermore, the waste discharged by 63,000 tons of finfish or the total amount of cultivated fish in Japan for the year of 1999 is equivalent to that of 5 million people [7]. Consequently, coastal eutrophication has been identified as on major ecological impact and one that disproportionally effects enclosed and coastal systems associated with finfish aquaculture. This highlights the need for the development of strategies that limit the output of nutrients as a means to protect the environment and to ensure the future expansion and intensification of finfish aquaculture is conducted in a sustainable manner. Therefore, the challenge that is presented is to develop methods and technologies that minimize the negative environmental impacts of finfish aquaculture wastes.

\footnotetext{
* ORCID: https://orcid.org/0000-0002-7446-855X
} 
Currently the most practical and economic solution for reducing the concentration of eutrophying compounds in finfish effluent is to treat it directly before it is discharged as waste into the environment. An alternative biological solution to this process is reported has been numerous studies [8]-[10]. By integrating macroalgae into the production process nutrients can be absorbed and concentrated from the effluent before discharged. In this sense the macroalgae acts as a biofilter, uptaking nutrients from the system. In addition to improving water quality, it has been suggested that the cultivation of macroalgae within finfish systems is a technology that can bring economic benefits to farm operations through additional revenue streams and the diversification of the organisms cultured [11], [12]. Several studies have reported the benefits of integrating macroalgae into the finfish culture process, however most of these studies have consisted primarily of small-scale laboratory experiments. As such, there is a present need for the scaling up of experimental systems in order to validate the feasibility of integrating macroalgae into real world farming operations.

In the present study we integrate the green macroalgae Ulva intestinalis, into a finfish aquaculture system with the aim to assess its ability to uptake waste nutrients and as a consequence its usefulness as a biofilter. As macroalgae has value outside of just its nutrient uptake ability, we simultaneously examined the production of macroalgal biomass and the safety of this biomass for use as feed material in terms of heavy metal concentrations in respect to European Union directives.

\section{MATERIALS AND METHOD}

The study on the growth and biofiltration capacity of the macroalgae Ulva intestinalis was conducted in open air conditions on the north coast of Saaremaa island, Estonia (latitude: 58.439559, longitude: 22.062178). The experiment was conducted over one vegetative season (2020) and comprised of three, 4-5 week growth trials. Wild grown $U$. intestinalis material for use in the experiment was collected from local coastal areas on Saaremaa island. $U$. intestinalis was selected as the biofilter because it is found to grow in large quantities locally. Additionally, it is characterized by its high nutrient uptake rates as reported by literature and confirmed by nutrient uptake trials conducted in the previous year that demonstrated it to have a better efficacy for nutrient uptake than that of other species found to occur naturally within the region. Upon collection the macroalgae material was cleaned of epiphytes and encrusting organisms before being placed in seawater filled containers and transported directly to the experiment site.

\subsection{Experimental protocol}

To test the biofiltration ability of Ulva intestinalis, a land based mesocosm experiment was constructed. The mesocosm experiment consisted of mesocosm chambers placed in four parallel series, 12 chambers in length. Each mesocosm chamber in the series was connected to the previous chamber with a pipe in such a manner that water could flowed through from the first mesocosm chamber into the subsequent chamber next in the series before outflowing as wastewater into the adjacent sea. The first mesocosm in each of the four series was connected with piping to a larger 6,000 1 mesocosm chamber that was stocked with Rainbow trout (Oncorhynchus mykiss) $(50 \mathrm{~kg})$. Wastewater from the trout stocked mesocosm flowed at an equal rate into each of the four series. Seawater was pumped, aerated and filtered from the Baltic sea directly into the trout stocked mesocosm providing a continuous flow of new water to the system. $U$. intestinalis material was weighed and stocked (approximately $2,000 \mathrm{~g}$ each) into each of the mesocosms ranked fourth, fifth and sixth from the initial mesocosm in three of the four series. The fourth series contained no macroalgal material and 
was designated the control series. Vigorous aeration was supplied via an air pump and tubing system to the fourth, fifth and sixth mesocosm in each of the series. Automatic loggers were used to continuously record factors of temperature $\left({ }^{\circ} \mathrm{C}\right)$, $\mathrm{pH}$ and dissolved oxygen $(\mathrm{mg} / \mathrm{L})$ for the trout mesocosm as well as the mesocosms tanks in series. Salinity (PSU) was measured for all mesocosms every 3.5 days using a portable sensor. The system was allowed to acclimatize for 3.5 days after the designated mesocosms were stocked before any sampling commenced. At the conclusion of each of the three trials the macroalgal material was removed and replaced with new material.

Water samples were taken in triplicate from the trout mesocosm as well as from the mesocosms ranked three, five, nine and twelve in each of the series and analyzed by an accredited water quality laboratory 3.5 days. Water samples were analysed for nutrient content (nitrite, nitrate, total nitrogen, phosphate and total phosphorus). Any macroalgae material found to be in poor condition was weighed and removed from the experiment. If the macroalgae material was found to be decaying the nutrient sample was discarded and sampling for that mesocosm deferred until the next sample period. As per government licensing requirements the nutrients were also monitored at the beginning and end of the experiment where water inflowed and outflowed from the experiment.

At the conclusion of each of the three trials the change in $U$. intestinalis weight from the initial stocked weight for each of the stocked mesocosms was recorded. Macroalgae material was retained from each of the macroalgae stocked mesocosm and was analyzed for trace metal concentrations.

\subsubsection{Statistical analysis}

In order to compare the nutrient concentrations between each of the three trials the recorded data was adjusted to the percentage change relative to the fish stocked mesocosm (mesocosm zero) for each of the sample mesocosms in the series. A students t-test was used to compare the means of macroalgae stocked mesocosms with the control. A significance level of $95 \%$ $(\alpha=0.05)$ was set for all tests. Macroalgae growth rate for each of the stocked mesocosms was calculated as percentage growth per day using the recorded initial and final waits and time.

\section{RESULTS}

\subsection{Nutrient removal}

The concentration of the nutrients tested was found to decrease throughout the mesocosm series. Both Nitrite and Nitrate were observed to be up taken by the mesocosms containing the macroalgae Ulva intestinalis when compared to the associated control. Under favorable growth conditions $U$. intestinalis demonstrated a significant increase in the uptake of both nitrate and nitrite resulting in a decrease of $18.4 \%$ and $25.2 \%$ of the nutrients respectively when compared to the control series (students t-test; $\mathrm{p}<0.05$ ) (Fig. 1). The phosphorous nutrient data was found to have a large degree of variability among the samples and due to this high variability, no significant difference between the control series and macroalgal stocked series for these nutrients was observed. Overall, the system demonstrated a high degree of nutrient removal efficiency, with up to $60 \%$ of both nitrate and nitrite removed from the system and $60 \%$ of phosphate and $30 \%$ of phosphorous also removed relative to concentration of nutrients measured in the trout mesocosm. 

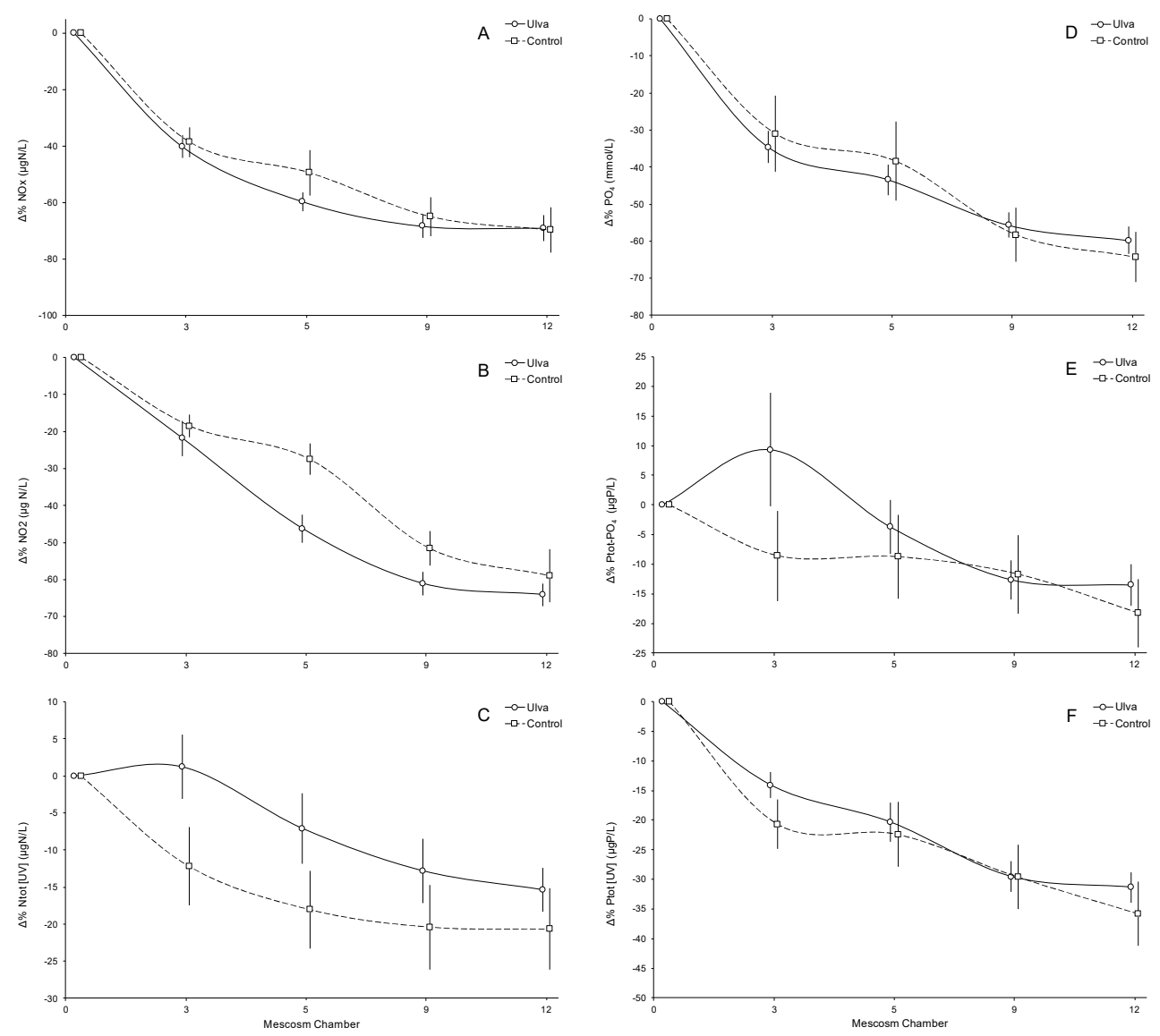

Figure 1: Change in the mean concentration of the nutrients $(\mathrm{A}=$ nitrite; $\mathrm{B}=$ nitrate; $\mathrm{C}=$ total nitrogen; $\mathrm{D}=$ phosphate; $\mathrm{E}=$ phosphorus; and $\mathrm{F}=$ total phosphorus) as a percentage relative to the initial trout stocked mesocosm across the mesocosm series. The mesocosms ranked four, five and six in the Ulva series were stocked with macroalgae. The control series contained no macroalgae. Error constructed as \pm 1 standard error.

\subsection{Physical parameters and biomass growth}

Water temperature was found to vary to a high degree throughout the experiment coinciding with air temperatures which followed typical diurnal and seasonal trends in temperature. The variation in temperature between the first and final tanks in the mesocosm series was recorded to be on average 3 degrees warmer than that of the final. The highest the water temperatures reached was 25 degrees in June. In contrast salinity remained highly stable throughout the experiment with little fluctuation and a mean PSU of 7.2 observed. Dissolved oxygen fluctuated following the expected trend of daytime photosynthesis and nighttime respiration. Mesocosm $\mathrm{pH}$ fluctuated to a similar degree in accordance with day and night cycles. When experiencing the appropriate abiotic factors for growth, $U$. intestinalis biomass was found to 
increase steadily over the course of the experiment. Mean biomass growth was recorded to be $1.9 \%$ per day (under growth conditions) with the highest growth observed occurring in the third growth trial at $4 \%$ per day.

Table 1: Mean $( \pm \mathrm{SE})$ nutrient concentration across the mesocosm series.

\begin{tabular}{|c|c|c|c|c|c|}
\hline & 0 & 3 & 5 & 9 & 12 \\
\hline \multicolumn{6}{|l|}{ NOx $(\mu \mathrm{g} \mathrm{N} / \mathrm{L})$} \\
\hline Ulva & $10.39 \pm 1.29$ & $5.95 \pm 0.75$ & $3.85 \pm 0.44$ & $2.91 \pm 0.3$ & $2.66 \pm 0.28$ \\
\hline $\begin{array}{l}\text { Control } \\
\text { NO2 }(\mu \mathrm{g} \mathrm{N} / \mathrm{L})\end{array}$ & $10.39 \pm 2.3$ & $6.19 \pm 1.34$ & $4.96 \pm 1.27$ & $3.25 \pm 0.69$ & $2.7 \pm 0.58$ \\
\hline Ulva & $1.19 \pm 0.12$ & $0.89 \pm 0.08$ & $0.69 \pm 0.06$ & $0.5 \pm 0.04$ & $0.46 \pm 0.04$ \\
\hline $\begin{array}{l}\text { Control } \\
\text { Ntot [UV] }(\mu \mathrm{g} \mathrm{N} / \mathrm{L})\end{array}$ & $1.19 \pm 0.21$ & $0.97 \pm 0.16$ & $0.83 \pm 0.14$ & $0.53 \pm 0.09$ & $0.45 \pm 0.07$ \\
\hline Ulva & $262.78 \pm 11.17$ & $257.15 \pm 11.13$ & $241.86 \pm 9.68$ & $228.46 \pm 7.48$ & $223.85 \pm 6.65$ \\
\hline $\begin{array}{l}\text { Control } \\
\mathrm{PO} 4(\mu \mathrm{g} \mathrm{P} / \mathrm{L})\end{array}$ & $262.78 \pm 19.83$ & $224.36 \pm 17.8$ & $211.67 \pm 19.55$ & $212.96 \pm 15.43$ & $205.58 \pm 9.9$ \\
\hline Ulva & $12.33 \pm 0.76$ & $9.03 \pm 0.8$ & $7.08 \pm 0.61$ & $5.69 \pm 0.44$ & $5.39 \pm 0.45$ \\
\hline $\begin{array}{l}\text { Control } \\
\text { Ptot-PO4 }(\mu \mathrm{g} \mathrm{P} / \mathrm{L})\end{array}$ & $12.33 \pm 1.34$ & $7.94 \pm 1.25$ & $6.82 \pm 1.23$ & $5.62 \pm 0.82$ & $4.75 \pm 0.77$ \\
\hline Ulva & $22.35 \pm 1.3$ & $24.42 \pm 1.66$ & $23.1 \pm 1.3$ & $21.42 \pm 1.33$ & $21.23 \pm 1.35$ \\
\hline $\begin{array}{l}\text { Control } \\
\text { Ptot [UV] }(\mu \mathrm{g} \mathrm{P} / \mathrm{L})\end{array}$ & $22.35 \pm 2.3$ & $21.01 \pm 2.42$ & $20.94 \pm 2.4$ & $21.46 \pm 2.3$ & $19.65 \pm 1.99$ \\
\hline Ulva & $35.53 \pm 1.93$ & $33.45 \pm 2.09$ & $30.18 \pm 1.47$ & $27.11 \pm 1.44$ & $26.62 \pm 1.41$ \\
\hline Control & $35.53 \pm 3.43$ & $28.95 \pm 2.66$ & $27.76 \pm 2.78$ & $27.08 \pm 2.51$ & $1.4 \pm 2.09$ \\
\hline
\end{tabular}

\subsection{Heavy metals}

The heavy metal analysis of Ulva intestinalis material for arsenic, lead, mercury and cadmium was conducted by an accredited laboratory and is reported in relation to the maximum accepted levels under the European Union directive for unwanted substances in animal feed (2002/32/EC). The concentration of arsenic was found to be near the limit of acceptable levels for animal feed $(2 \mathrm{mg} / \mathrm{kg}(2002 / 32 / \mathrm{EC}))$ but was much lower than the maximum level of seaweed meal and feed material made from seaweed $(40 \mathrm{mg} / \mathrm{kg}$ $(2012 / 744 / E U))$. Excluding one sample which was found to have concentrations several times higher than the allowable maximum, lead levels in the sample $U$. intestinalis material were found to be below the established limits of $10 \mathrm{mg} / \mathrm{kg}(2002 / 32 / \mathrm{EC})$ for green fodder (2012/744/EU; 2013/1275/EU). The mercury content of all macroalgal samples analyzed was found to be below the maximum level of $0.1 \mathrm{mg} / \mathrm{kg}(2002 / 32 / \mathrm{EC})$ for feed material. In all macroalgal samples analyzed, cadmium content was found to be considerably lower than that of the maximum allowable level of $1 \mathrm{mg} / \mathrm{kg}(2002 / 32 / \mathrm{EC})$ for feed material of plant origin.

Table 2: Heavy metal concentration of Ulva intestinalis cultivated under enhanced nutrient conditions.

\begin{tabular}{lcc}
\hline & Range & Mean \pm SD \\
\hline Arsenic $(\mathrm{mg} / \mathrm{kg})$ & $4.8-2.2$ & $3.27 \pm 1.17$ \\
Cadmium $(\mathrm{mg} / \mathrm{kg})$ & $0.09-0.06$ & $0.07 \pm 0.01$ \\
Lead $(\mathrm{mg} / \mathrm{kg})$ & $12.0-3.6$ & $7.58 \pm 3.54$ \\
Mercury $(\mathrm{mg} / \mathrm{kg})$ & $0.03-0.01$ & $<0.02 \pm 0.01$ \\
\hline
\end{tabular}




\section{DISCUSSION}

The effluent produced by finfish aquaculture poses numerous detrimental effects to the environment through excessive nutrient loading [4]-[6]. The cultivation of macroalgae in a manner that is integrated into finfish aquaculture operations is suggested as a means to offset these environmental impacts and improve water quality [8]-[10]. Within this context, the macroalgae species Ulva intestinalis used in this study demonstrates its potential to efficiently remove some of these eutrophying compounds. In particular U. intestinalis demonstrated useful potential in the efficient removal of nitrite and nitrate from the growth medium and as a consequence improved water quality. Past laboratory-based studies have indicated macroalgae species such as Gracilaria and Ulva constitute ideal candidates for use in integrated biofiltration systems within a wastewater and polyculture context. An example being Hernández et al. [9] which investigated Ulva rotundata, Enteromorpha intestinalis, Gracilaria gracilis for their biofiltration capacity of waste effluents produced by Sea bass (Dicentrarchus labrax) with small scale experiments. They demonstrated these species to be useful biofilters but concluded that the scaling up of biofiltration designs and integration into finfish aquaculture system was necessary in order to adequality evaluate a given species utility. The present study represents this scaling up and confirms $U$. intestinalis as species suitable for integration into current land-based aquaculture operations as a biofilter.

Although $U$. intestinalis is an efficient nitrogen filter with a relatively small amount of macroalgal material (i.e. $\sim 2,000 \mathrm{~g}$ wet weight) removing significant concentrations of nitrogen based nutrients from the system relative to the density of the stocked fish, it absorbed little in the way of phosphorus based nutrients. Such a result is consistent with findings in the literature which states Ulva species as having a lower affinity for and slower uptake of phosphorus when compared with nitrogen [13], [14]. It is therefore suggested that finfish aquaculture operations may see a benefit in culturing macroalgae species with a strong affinity for phosphorus compounds in tandem with $U$. intestinalis as a means to uptake the full spectrum of eutrophying dissolved compounds produced by finfish effluent. Such a system could act as a highly efficient, low cost, biofiltration system.

The cultivation of macroalgae alongside onshore finfish facilities may be an attractive solution to improving water quality for farm operators. Nevertheless, for operations to be successful care must be taken in order to ensure the macroalgae is cultivated under the correct growth conditions. For instance, in outdoor operations such as the one experimented with in this study, temperatures spikes represented a serious issue, at times resulting in the die off of portions of the macroalgal material. Such die offs result in an inefficient system being less efficient and counter the filtration goal as decaying material releases additional nutrients into back into the system. Additionally, water flow through rates must be carefully calibrated to ensure adequate nutrients are supplied to the macroalgae with considerations made for the macroalgae stocked at the end of the flow through series where nutrients may have already been stripped from the water leading to starvation. In this regard, it may make sense for aquaculture operations to implement designs that incorporate a larger number of shorter flow through series as means to avoid macroalgae experiencing limited nutrients.

The nutrients stripped from the finfish wastewater mesocosm resulted in an increase in Ulva intestinalis biomass. Such growth represents a potential economic opportunity to finfish aquaculture operation as macroalgae biomass holds value for numerous industries and is typically highly difficult to obtain in industrial quantities. For instance, macroalgae and more specifically Ulva has numerous applications in industries ranging from Food, medicine, therapeutics feed and fertilizers [11]. At its peak we obtained a growth rate of $4 \%$ per day by wet weight with a system not specifically optimized for growth. Temperature appeared to be the major restricting factor with the open-air system experiencing midday temperature spikes 
resulting in acute stress for $U$. intestinalis in the mesocosms. With improved designs, which could be as simple as providing shades to block direct light for the mesocosms, operations can likely further improve growth rates. In this sense future onshore aquaculture operations may take advantage of developing alternative revenue streams through grown biomass having the overall effect of increasing both farm profitability and sustainability.

To ensure the safety and suitability of $U$. intestinalis enriched by finfish effluent for consumption by humans or as an additive to animal feed, the macroalgae material was analyzed for its heavy metal concentrations in relation to guidelines set out by the European Union (2002/32/EC). All samples bar one, which was found to contain high levels of lead (likely contamination by lead weights used to secure aeration hoses) and was excluded, were found to be within the maximum limit for safe consumption for the heavy metals arsenic, lead, mercury and cadmium. By nature, $U$. intestinalis is a fast-growing species and as such its high turnover is unlikely to accumulate appreciable amounts of heavy metals from its environment before it is harvested. As such, there is no indication from this study that a fast growing macroalgae produced from a biofiltration system would represent a substantial threat to either human or animal health due to high heavy metal concentrations.

Integrating macroalgae into aquaculture systems offers a biological solution to the issue of nutrient loading from wastes associated with intensive finfish cultivation. The present study demonstrates Ulva intestinalis' ability as species to prevent $\mathrm{N}$ loading from finfish effluent and to improve water quality. The results validate previous past laboratory-based studies that have suggested biofilters can be scaled for use in real world aquaculture systems. This study also further supports that the production of macroalgae biomass cultivated alongside finfish aquaculture can provide economic opportunities for farming operations.

\section{ACKNOWLEDGEMENTS}

This study was funded by European Maritime and Fisheries Fund through special project call organized by Estonian Ministry of Rural affairs (Project number 821017780003). We would like to thank Ösel Aquafarms OÜ and Ösel Harvest OÜ and especially Andro Ots and Henry Ots for good cooperation and providing with experimental site and needed fishfarming equipment. Special thanks go to Kaido Noormägi for maintaining the trout mesocosm. Thanks to Marin Teeveer and Teemar Püss for constructing the mesocosm experiment. We thank Hanna-Eliisa Luts for assistance with macroalgae sample collection and all staff of the department of Marine Biology of Estonian Marine Institute who assisted us in the process.

\section{REFERENCES}

[1] Pauly, D., Watson, R. \& Alder, J., Global trends in world fisheries: impacts on marine ecosystems and food security. Philosophical Transactions of the Royal Society: Biological Sciences. 360(1453), pp. 5-12, 2005.

https://doi.org/10.1098/rstb.2004.1574.

[2] Bostock, J. et al., Aquaculture: global status and trends. Philosophical Transactions of the Royal Society B: Biological Sciences. 365(1554) pp. 2897-2912, 2010. https://doi.org/10.1098/rstb.2010.0170.

[3] Huntington, T.C. \& Hasan, M.R., Fish as feed inputs for aquaculture practices, sustainability and implications: A global synthesis. FAO Fisheries and Aquaculture Technical Paper, 518, pp. 1-61, 2009.

[4] Wang, J., Beusen, A.H., Liu, X. \& Bouwman, A.F., Aquaculture production is a large, spatially concentrated source of nutrients in Chinese freshwater and coastal seas. Environmental Science and Technology. 54(3), pp. 1464-1474, 2019.

https://doi.org/10.1021/acs.est.9b03340. 
[5] Iwama, G.K., Interactions between aquaculture and the environment. Critical Reviews in Environmental Science and Technology. 21(2), pp. 177-216, 1991.

https://doi.org/10.1080/10643389109388413.

[6] Herbeck, L.S., Unger, D., Wu, Y. \& Jennerjahn, T.C., Effluent, nutrient and organic matter export from shrimp and fish ponds causing eutrophication in coastal and backreef waters of NE Hainan, tropical China. Continental Shelf Research, 57, pp. 92-104, 2013. https://doi.org/10.1016/j.csr.2012.05.006.

[7] Suzuki, Y., Maruyama, T., Numata, H., Sato, H. \& Asakawa, M., Performance of a closed recirculating system with foam separation, nitrification and denitrification units for intensive culture of eel: towards zero emission. Aquacultural Engineering, 3-4, pp. 165-182, 2003. https://doi.org/10.1016/j.aquaeng.2003.08.001.

[8] Marinho-Soriano, E., Nunes, SO., Carneiro, M.A., Pereira, D.C., Nutrients' removal from aquaculture wastewater using the macroalgae Gracilaria birdiae. Biomass and Bioenergy, 33(2), pp. 327-331 2009. https://doi.org/10.1016/j.biombioe.2008.07.002.

[9] Hernández, I., Martínez-Aragón, J.F., Tovar, A., Pérez-Lloréns, J.L. \& Vergara, J.J., Biofiltering efficiency in removal of dissolved nutrients by three species of estuarine macroalgae cultivated with sea bass (Dicentrarchus labrax) waste waters 2. Ammonium. Journal of Applied Phycology, 5, pp. 375-384, 2002. https://doi.org/10.1023/A:1022134701273.

[10] Hernández, I., Fernández-Engo, M.A., Pérez-Lloréns, J.L. \& Vergara, J.J., Integrated outdoor culture of two estuarine macroalgae as biofilters for dissolved nutrients from Sparus auratus waste waters. Journal of Applied Phycology, 6, pp. 557-567, 2005. https://doi.org/10.1007/s10811-005-9006-6.

[11] Dominguez, H. \& Loret, E.P., Ulva lactuca, a source of troubles and potential riches. Marine Drugs, 6, p. 357, 2019. https://doi.org/10.3390/md17060357.

[12] Chopin., T. et al., Integrating seaweeds into marine aquaculture systems: A key toward sustainability. Journal of Phycology, 37(6), pp. 975-986. 2001. https://doi.org/10.1046/j.1529-8817.2001.01137.x.

[13] Li, S., Yu, K., Huo, Y., Zhang, J., Wu, H., Liu, Y., Shi, D. \& He, P., Effects of nitrogen and phosphorus enrichment on growth and photosynthetic assimilation of carbon in a green tide-forming species (Ulva prolifera) in the Yellow Sea. Hydrobiologia, 776(1), pp. 161-171, 2016. https://doi.org/10.1007/s10750-016-2749-z.

[14] Luo, M.B., Liu, F. \& Xu, Z.L., Growth and nutrient uptake capacity of two cooccurring species, Ulva prolifera and Ulva linza. Aquatic Botany, 100, pp. 18-24, 2012. https://doi.org/10.1016/j.aquabot.2012.03.006. 